\title{
Exploration of Victoria Crater by the Mars Rover Opportunity
}

\section{Citation}

Squyres, Steven W., Andrew H. Knoll, Raymond E. Arvidson, James W. Ashley, James F. III Bell, Wendy M. Calvin, Philip R. Christensen, et al. 2009. Exploration of Victoria Crater by the Mars rover Opportunity. Science 324(5930): 1058-1061.

\section{Published Version}

doi:10.1126/science.1170355

\section{Permanent link}

http://nrs.harvard.edu/urn-3:HUL.InstRepos:3934552

\section{Terms of Use}

This article was downloaded from Harvard University's DASH repository, and is made available under the terms and conditions applicable to Open Access Policy Articles, as set forth at http:// nrs.harvard.edu/urn-3:HUL.InstRepos:dash.current.terms-of-use\#OAP

\section{Share Your Story}

The Harvard community has made this article openly available.

Please share how this access benefits you. Submit a story.

Accessibility 


\section{Exploration of Victoria Crater by the Rover Opportunity}

S.W. Squyres ${ }^{1}$, A.H. Knoll ${ }^{2}$, R.E. Arvidson ${ }^{3}$, J.W. Ashley ${ }^{4}$, J.F. Bell III' ${ }^{1}$, W.M. Calvin ${ }^{5}$, P.R. Christensen $^{4}$, B.C. Clark ${ }^{6}$, B.A. Cohen ${ }^{7}$, P.A. de Souza Jr. ${ }^{8}$, L. Edgar ${ }^{9}$, W.H. Farrand ${ }^{10}$, I. Fleischer $^{11}$, R. Gellert ${ }^{12}$, M.P. Golombek ${ }^{13}$, J. Grant ${ }^{14}$, J. Grotzinger ${ }^{9}$, A. Hayes ${ }^{9}$, K.E. Herkenhoff $^{15}$, J.R. Johnson ${ }^{15}$, B. Jolliff ${ }^{3}$, G. Klingelhöfer ${ }^{11}$, A. Knudson ${ }^{4}$, R. $\mathrm{Li}^{16}$, T.J. McCoy ${ }^{17}$, S.M. McLennan ${ }^{18}$, D.W. Ming ${ }^{19}$, D.W. Mittlefehldt ${ }^{19}$, R.V. Morris ${ }^{19}$, J.W. Rice Jr. ${ }^{4}$, C. Schröder ${ }^{11}$, R.J. Sullivan ${ }^{1}$, A. Yen ${ }^{13}$, R.A. Yingst ${ }^{20}$

${ }^{1}$ Dept. of Astronomy, Space Sciences Bldg., Cornell University, Ithaca, NY 14853, USA

${ }^{2}$ Botanical Museum, Harvard University, Cambridge MA 02138, USA

${ }^{3}$ Dept. of Earth and Planetary Sciences, Washington University, St. Louis, MO 63031, USA

${ }^{4}$ School of Earth and Space Exploration, Arizona State University, Tempe, AZ 85287, USA

${ }^{5}$ University of Nevada, Reno, Geol. Sci., Reno, NV 89557, USA

${ }^{6}$ Lockheed Martin Corporation, Littleton, CO 80127, USA

${ }^{7}$ NASA Marshall Space Flight Center, Huntsville, AL 35812, USA

${ }^{8}$ Tasmanian ICT Centre, CSIRO, Castray Esplanade, Hobart TAS 7000, Australia

${ }^{9}$ Division of Geological and Planetary Sciences, Caltech, Pasadena, CA 91125, USA

${ }^{10}$ Space Science Institute, Boulder, CO 80301, USA

${ }^{11}$ Institut für Anorganische und Analytische Chemie, Johannes Gutenberg-Universität, Mainz, Germany

${ }^{12}$ Department of Physics, University of Guelph, Guelph, ON, N1G 2W1, Canada

${ }^{13}$ Jet Propulsion Laboratory, California Institute of Technology, Pasadena, CA 91109, USA

${ }^{14}$ Center for Earth and Planetary Studies, Smithsonian Institution, Washington, D.C. 20560, USA

${ }^{15}$ U.S. Geological Survey, Flagstaff, AZ 86001, USA

${ }^{16}$ Dept. of Civil \& Env. Eng. \& Geodetic Science, Ohio State University, Columbus, OH 43210, USA

${ }^{17}$ Department of Mineral Sciences, National Museum of Natural History, Smithsonian Institution, Washington, DC 20560, USA

${ }^{18}$ Dept. of Geosciences, State University of New York, Stony Brook, NY 11794, USA

${ }^{19}$ ARES, NASA Johnson Space Center, Houston, TX 77058, USA

${ }^{20}$ Natural and Applied Sciences, University of Wisconsin Green Bay, Green Bay, WI 54311, USA

Submitted to Science

December 28, 2008 


\begin{abstract}
The Mars rover Opportunity has explored Victoria crater, a 750-meter eroded impact crater formed in sulfate-rich sedimentary rocks. Impact-related stratigraphy is well preserved in the crater walls, and meteoritic debris is present near the crater rim. The size of hematite-rich concretions in the bedrock decreases up section, documenting systematic variation in the intensity of groundwater processes. Sedimentary layering in the crater walls preserves evidence of ancient wind-blown dunes. Compositional variations with depth in the bedrock mimic those $\sim 6 \mathrm{~km}$ to the north, and demonstrate that water-induced alteration of rocks at Meridiani Planum was regional in scope.
\end{abstract}


Geologists have built an understanding of Earth's environmental history through the documentation of sedimentary rocks exposed in stratigraphic sections. Key to this understanding is the comparison of sections exposed in different places, allowing evaluation of the regional extent of patterns established locally. Because of its unanticipated longevity, the Mars Exploration Rover Opportunity has been able to examine three stratigraphic sections distributed over a linear distance of more than six kilometers at Meridiani Planum. Initial documentation of a $35 \mathrm{~cm}$ exposure near Opportunity's landing site in Eagle crater (1) was followed by analysis of more than $7.5 \mathrm{~m}$ of stratigraphy in the wall of Endurance crater, some $800 \mathrm{~m}$ to the east (2). Here we report on Opportunity's examination of a third section, more than $10 \mathrm{~m}$ thick, exposed in cliffs along the margin of Victoria crater, a large impact structure some six km south of both Eagle and Endurance. Victoria data allow us to understand better the major geological themes and variations of late Noachian sedimentary rocks that underlie the Meridiani plains, showing that major depositional and diagenetic processes originally recognized locally have a regional extent.

Exploration of Victoria (Fig. 1) began on Sol 952 (3) with a clockwise traverse along the crater's northern rim, imaging cliff faces to document exposed stratigraphy at high resolution. Opportunity then returned to a location named Duck Bay (4) and descended into the crater on Sol 1293 to begin in-situ physical and chemical stratigraphic observations. Exiting the crater on Sol 1634, Opportunity performed more imaging to the southwest of Duck Bay before leaving Victoria.

Victoria crater is roughly 750 meters in diameter and 75 meters deep. Its outline is serrated, displaying sharp, steep promontories separated by rounded, more gently sloping alcoves. The crater has a raised rim $\sim 4-5 \mathrm{~m}$ high and $\sim 120-220 \mathrm{~m}$ wide, and is surrounded by an 
annulus of smooth terrain that extends approximately one crater diameter from the rim. The location and extent of this annulus suggest that it is derived from the crater's original ejecta blanket. Such features, along with observed crater morphology and ejecta thickness (exposed in upper interior walls), indicate that Victoria formed as a primary crater $\sim 600 \mathrm{~m}$ in diameter and $\sim 125 \mathrm{~m}$ deep (5). On the floor of the crater is a dune field $\sim 240 \times 320 \mathrm{~m}$ in size. The crater has been widened by erosion, and its depth reduced by deposition of wind-blown sand and material released from the crater walls. Eolian erosion and mass wasting have contributed to the development of alcoves and promontories.

Observations elsewhere at Meridiani have demonstrated that the sulfate-rich sedimentary rocks excavated during crater formation are highly susceptible to erosion by eolian abrasion $(1,2)$. Therefore, the annulus, although derived from the original continuous ejecta blanket, preserves no perched ejecta blocks - they have been planed off by eolian abrasion and covered by annulus soil. Ejecta debris currently is exposed only in the uppermost interior walls of the crater, and very near the rim where soil cover is discontinuous. There is no evidence that the impact excavated through the Meridiani sediments into an underlying non-sedimentary basement unit.

Small hematite-rich spherules interpreted as concretions characterize sedimentary rocks exposed throughout the Meridiani region $(1,2)$. Opportunity gained more than $30 \mathrm{~m}$ of elevation during the traverse from Endurance to Victoria; because regional outcrop is flat-lying, the path to Victoria was probably a traverse up section. Spherule size observed in outcrop shows a systematic decrease with elevation (and distance south of Endurance; 6-8; Fig. 2). Our observations therefore suggest that spherule size in bedrock decreases up section, documenting 
systematic variation in the intensity of groundwater processes in the wake of sulfate-rich sand deposition.

Once Opportunity entered the Victoria annulus, large spherules reappeared in the soil and soil coverage over bedrock became continuous. The source of these spherules is suggested by inspection of ejecta blocks preserved within in the crater wall at the Cape of Good Hope. These blocks exhibit purple-gray colors in Pancam (9) false-color views (10), distinct from typical outcrop rocks (Fig. 3). Pancam spectra of these blocks are correspondingly unusual, exhibiting negative 754-1009 nm slopes and weaker $535 \mathrm{~nm}$ band depths than typical "purple" rocks (11). Among these blocks, one called Cercedilla was chosen for study. Unlike all bedrock observed close to Victoria, Cercedilla contains large (up to $\sim 6 \mathrm{~mm}$ ) hematite-rich spherules.

Cercedilla was abraded using the Rock Abrasion Tool (RAT) (12) (Fig. 3c) and imaged with the Microscopic Imager (MI) (13), revealing large spherules and an additional population of possible small spherules $<0.5 \mathrm{~mm}$ in diameter. The elemental chemistry of Cercedilla revealed by the Alpha Particle X-Ray Spectrometer (APXS) (14) is also similar to that in the deepest part of the Karatepe stratigraphic section at Endurance crater (15) and is distinct from that in the Duck Bay section in Victoria crater described below, notably in having lower $\mathrm{FeO}_{\mathrm{T}} / \mathrm{Al}_{2} \mathrm{O}_{3}$ (where $\mathrm{FeO}_{\mathrm{T}}$ is total iron expressed as $\mathrm{FeO}$ ) and no $\mathrm{Cl}$ enrichment.

Consistent with the hypothesis that near-surface strata at Endurance are buried more deeply at Victoria, Cercedilla and other spectrally similar blocks nearby (Fig. 3) probably represent materials excavated during crater formation from a deeper stratigraphic unit within Victoria crater. The abundance of large spherules in Cercedilla further supports the idea that the spherules in the annulus were released by erosion from deeply-sourced, spherule-rich ejecta, similar to strata exposed in the walls of Eagle and Endurance craters. 
The distribution of spherules in the soil may explain another prominent feature of the regional landscape. Opportunity did not encounter large ripples during its traverse from Eagle to Endurance, but as it drove south toward Victoria, large ripples became prominent as mean spherule size declined. The Victoria annulus, covered as it is by large spherules eroded from ejecta blocks, again lacks large, coarse-grained ripples, suggesting that accumulations of larger spherules create dense, protective lags that impede eolian transport, stabilizing the soil and inhibiting ripple development.

Opportunity encountered an extended field of loose rocks on the Cabo Anonimo promontory. All have similar Pancam Vis/NIR spectral properties, including spectral absorption features consistent with the presence of olivine and/or low-Ca pyroxene. Miniature Thermal Emission Spectrometer (Mini-TES) (16) spectra of the 12 rocks observed are also mutually similar; together these observations imply a common composition for all the rocks in the field.

One rock, Santa Catarina $(\sim 11 \mathrm{x} 14 \mathrm{~cm})$, was chosen for detailed analysis. MI images showed a brecciated appearance, with some clasts exhibiting possible igneous quench textures (Fig. 4). Mössbauer (17) spectra confirmed the presence of olivine and pyroxene, and also revealed troilite. The elemental chemistry of Santa Catarina is unusual for Meridiani, but closely approximates that of Barberton (18), a $\sim 3-\mathrm{cm}$ pebble encountered at the rim of Endurance crater. Kamacite, an iron-nickel alloy, was identified in Barberton. Barberton is therefore probably a meteorite, and its composition is consistent with a mesosiderite silicate clast (18). We suggest that Santa Catarina, and by extension the other rocks in the field on Cabo Anonimo, are meteoritic, as well. Troilite is more abundant than metal in silicate clasts of the Vaca Muerta mesosiderite (19), and it is possible that some troilite in Santa Catarina remained while the metal phase was completely altered. Mössbauer spectra show that Santa Catarina contains a higher 
fraction of ferric iron than Barberton, which may indicate a higher degree of alteration.

Alternatively, Santa Catarina may contain kamacite clasts that were not detected because of heterogeneity in the breccia. If Santa Catarina and Barberton are indeed mesosiderite fragments, they may be related, because mesosiderites are relatively rare and these rocks were found within a few $\mathrm{km}$ of one another. The location of Santa Catarina allows the possibility that it and nearby rocks are fragments of the impactor that created Victoria crater.

Figure 5 shows typical impact-related stratigraphy at Victoria crater. The lowermost unit is intact bedrock. This grades upward into rock that is increasingly fractured but still in place, as shown by bedding planes that retain their original orientation. The fracturing probably took place during the cratering event, as the impact-induced shock wave impinged on the free surface, loading rocks in tension. Immediately above the pre-impact surface there is an abrupt transition to the crater's ejecta blanket up to $3 \mathrm{~m}$ of poorly sorted ejecta blocks with bedding planes in random orientations.

Pancam observations of the crater walls show distinctive horizontal color and albedo banding in the bedrock immediately below the pre-impact surface (Fig. 6). The uppermost unit (Steno; fractured but in place) has a blue-to-red slope and a $535 \mathrm{~nm}$ band depth that are low compared to the underlying unit (Smith). The color properties of these units are similar, respectively, to the darker-toned and lighter-toned rock spectral classes observed elsewhere at Meridiani (11). The next lower unit (Lyell) is spectrally similar to Steno. This sequence of an upper dark-toned unit underlain by a lighter-toned redder unit, and in turn by another darkertoned unit, was also observed in Endurance crater (11).

A number of promontories were imaged from the crater rim at scales of $\sim 1-3 \mathrm{~cm} / \mathrm{pixel}$. "Super resolution" techniques that combine information from multiple images (20) were used at 
Cape St. Mary, Cape St. Vincent, and Cape Verde. All observed promontories are dominated by eolian facies. No clasts are visible at Pancam resolution, consistent with the exclusively sandsized grains in all other Meridiani outcrops observed by Opportunity. Bedding is clearly distinguishable everywhere. Meter-scale eolian cross stratification is visible in several promontories, including Cape St. Mary and Cape St. Vincent (Fig. 7). Elsewhere bedding is massive, planar, or observed as low-angle climbing translatent cross-strata.

Cape St. Vincent presents a west-facing outcrop dominated by a 8-m vertical exposure of climbing translatent cross-strata. The stratification suggests sub-critical climbing bedforms with decameter-scale dune heights that migrated in a direction approximately parallel to the outcrop face. The color and albedo banding below the pre-impact surface is prominent at Cape St. Vincent. The banding is nearly horizontal, and is cut by bedding at a high angle. This relationship shows that the banding is not a primary depositional feature, but rather is diagenetic in origin.

Cape St. Mary presents a south-facing outcrop dominated by a 6-m vertical exposure of meter-scale sets of trough cross-bedding (bedding concordant with set boundaries). This layering is indicative of decameter-scale, sinuous-crested, eolian sand dunes migrating approximately perpendicular to the face of the outcrop. No erosional contacts are observed.

Cape Verde was imaged from within the crater, and shows evidence for a possible erosional contact at its base (Fig. 8). This contact can also be interpreted as a deflation surface or a set boundary in a larger dune complex. The lowermost unit is dominated by thickly bedded dune toeset laminae, which transition into finer bedded climbing translatent strata, with evidence for superimposed wind ripples. Evidence for diagenesis at Cape Verde includes truncated and 
cross-cutting facture fills, preferentially eroded bedding, and ribbed weathering superimposed on cross-strata, which we interpret as differential cementation.

The meter-scale cross-stratification at Victoria crater is comparable to Jurassic-age eolian deposits of the western US, and is interpreted to represent a dry dune field. The grain size, scale, angle of exposed bedding, and lack of any volcanic bombs or other outsized clasts are inconsistent with a pyroclastic origin for these deposits $(21,22)$.

As Opportunity descended into Victoria crater at Duck Bay, we performed a series of textural and compositional observations similar to those completed in Endurance crater (2). Along the rover's ingress path, the Steno, Smith, and Lyell units dip $\sim 2^{\circ}$ to the west. All are sulfate-rich sandstone. Steno has a vertical thickness of $\sim 70 \mathrm{~cm}$, and is fine-to-medium-grained ( 180-300 $\mu \mathrm{m})$, with well-defined laminae. Centimeter-to-meter scale cross-bedding is visible in places, and spherules are abundant. Steno and Smith are separated by an erosional contact marked on Opportunity's ingress path by a low-angle disconformity. Pancam stereo data indicate that the contact surface dips $\sim 10^{\circ}$ to the east. Smith has a vertical thickness of $\sim 80 \mathrm{~cm}$, and is smoother and lighter-toned than Steno and Lyell. Imaging at low solar incidence angles reveals fine planar laminations. Spherules are slightly less common than in Steno.

The Smith-Lyell contact is gradational. Lyell is darker than Smith in Pancam images, largely because of basaltic sand trapped on the outcrop surface in exposed pores in the rock. It is a well-sorted, fine-grained sandstone $(\sim 150-240 \mu \mathrm{m})$ with a vertical thickness of $1.85 \mathrm{~m}$ and prominent mm-to-cm scale laminations. Meter-scale cross-bedding is observed. Spherules are more common than in either Smith or Steno. The porosity in Lyell comes partly in the form of tabular prismatic vugs, similar to those observed by Opportunity at Eagle crater (23), but smaller in size. 
Elemental compositions at Duck Bay (Fig. 9) fall mostly within established ranges for Meridiani, but with higher Fe concentrations; the lowermost unit investigated (Gilbert, immediately below Lyell) has the highest Fe content yet measured in Meridiani bedrock. Other elements that are commonly associated with $\mathrm{Fe}$, including $\mathrm{Ti}, \mathrm{Mn}, \mathrm{Cr}$ and $\mathrm{Ni}$, display no enhancements. All rocks are sulfate-rich; Steno has the highest S concentration of any bedrock observed at Meridiani.

Higher Fe aside, observed stratigraphic trends in Victoria outcrop chemistry compare closely to those measured at Endurance. Both measured sections show down-section decreases in $\mathrm{S}, \mathrm{Fe}$, and $\mathrm{Mg}$; and corresponding $\mathrm{Al}$ and $\mathrm{Si}$ enrichment. Both sections also show a sharp discontinuity in $\mathrm{Cl}$ content; stratigraphically lower parts of the sections at both craters are 2-3 times higher than uppermost units. At Duck Bay, the main chemical discontinuity coincides with the Smith - Lyell contact, likely corresponding to a diagenetic boundary, as inferred from Pancam observations. $\mathrm{Cl}$ discontinuities correspond to a stratigraphic level slightly above the point at which systematic decreases in $\mathrm{MgO} / \mathrm{Al}_{2} \mathrm{O}_{3}$ and $\mathrm{FeO}_{\mathrm{T}} / \mathrm{Al}_{2} \mathrm{O}_{3}$ begin (Fig. 9).

Measured stratigraphic sections at Endurance and Victoria are similar in character but differ in stratigraphic detail, consistent with evidence that Victoria rocks lie stratigraphically above those exposed in Endurance. The systematic decrease in spherule size described above similarly suggests early diagenetic processes that persisted through time, but with quantitative variation. What, then, do we make of the similar chemical and color stratigraphy for two sections separated by $\sim 6 \mathrm{~km}$ ?

On the basis of cross-cutting relationships, textural features at Endurance crater have been interpreted as relatively late diagenetic events (24) thought to record chemical interaction 
with a local groundwater table $(21,24)$. If correct, the observation of comparable vertical trends in sections that may represent distinct stratigraphic levels could imply that a limited set of depositional and early diagenetic processes recurred through time during regional stratigraphic development. Alternatively, Amundson et al. (25) have proposed that chemostratigraphic trends at Endurance may reflect downward penetrating diagenesis related to surface exposure. This would allow chemical trends in both sections to reflect a single alteration event that took place during or after development of the current land surface or in response to impact processes that gave rise to Endurance and Victoria craters. In either case, the wettest conditions recorded regionally occurred during deposition and early diagenesis, with progressive drying thereafter (20).

Opportunity's investigation of Victoria crater shows that depositional, diagenetic and erosional processes documented locally at Eagle and Endurance craters acted regionally at Meridiani Planum. Indeed, integration of outcrop observations with orbital data suggests that the surficial processes recorded most prominently at Meridiani have been globally important. These processes include (i) chemical interaction of basalts and acidic water to produce sulfate salts; (ii) generation, transport by wind, and deposition of sands, with ground water-influenced cementation permitting vertical accretion of strata; (iii) later diagenetic alteration of outcrop surfaces under increasingly arid conditions; and (iv) erosion of friable sedimentary rocks by persistent wind action, continuing to the present.

\section{References and Notes}

1. S.W. Squyres et al., Science 306, 1698 (2004).

2. S.W. Squyres et al., Science 313, 1403 (2006).

3. A sol is defined as one martian solar day.

4. All of the names of promontories and alcoves at Victoria crater are taken from places explored on Ferdinand Magellan's voyage of circumnavigation. 
5. J.A. Grant et al., J. Geophys. Res. 113, E11010, doi:10.1029/2008JE003155 (2008).

6. C. Weitz et al., J. Geophys. Res. 111, E12S04, doi:10.1029/2005JE002541 (2006).

7. W.M. Calvin et al., J. Geophys. Res. 113, E12S37, doi:10.1029/2007JE003048 (2008).

8. K.E. Herkenhoff et al., J. Geophys. Res. 113, E12S32, doi:10.1029/2008JE003100 (2008).

9. J.F. Bell III et al., J. Geophys. Res. 108, 8063, doi:10.1029/2003JE002070 (2003).

10. Colors based on contrast-stretched red-green-blue composites from Pancam's 673, 535, and $432 \mathrm{~nm}$ filters.

11. W.H. Farrand et al., J. Geophys. Res. 112, E06S02, 10.1029/2006JE002773 (2007).

12. S. Gorevan et al., J. Geophys. Res. 108, 8068, doi:10.1029/2003JE002061 (2003).

13. K.E. Herkenhoff et al., J. Geophys. Res. 108, 8065, doi:10.1029/2003JE002076 (2003).

14. R. Rieder et al., J. Geophys. Res. 108, 8066, doi:10.1029/2003JE002150 (2003).

15. B.C. Clark et al., Earth Planet. Sci. Lett. 240, 73 (2005).

16. P.R. Christensen et al., J. Geophys. Res. 108, 8064, doi:10.1029/2003JE002117 (2003).

17. G. Klingelhöfer et al., J. Geophys. Res. 108, 8067, doi:10.1029/2003JE002138 (2003).

18. C. Schröder et al., J. Geophys. Res. 113, E06S22, doi:10.1029/2007JE002990 (2008).

19. M. Kimura et al., Proc. NIPR Symp. Antarct. Meteorites 4, 263-306 (1991).

20. J.F. Bell III et al., J. Geophys. Res. 111, E02S03, doi:10.1029/2005JE00244 (2006).

21. J.P. Grotzinger et al., Earth Planet. Sci. Lett. 240, 11 (2005).

22. K.E. Herkenhoff et al., J. Geophys. Res. 113, E12S32, doi:10.1029/2008JE003100 (2008).

23. S.W. Squyres et al., Science 306, 1709 (2004).

24. S.M. McLennan et al., Earth Planet. Sci. Lett. 240, 95 (2005).

25. R. Amundson et al., Geochim. Cosmochim. Acta 72, 3845 (2008).

26. A.H. Knoll et al., J. Geophys. Res. 113, E06S16, doi:10.1029/2007JE002949 (2008).

27. This research was carried out for the Jet Propulsion Laboratory, California Institute of Technology, under a contract with NASA. 


\section{Figures:}

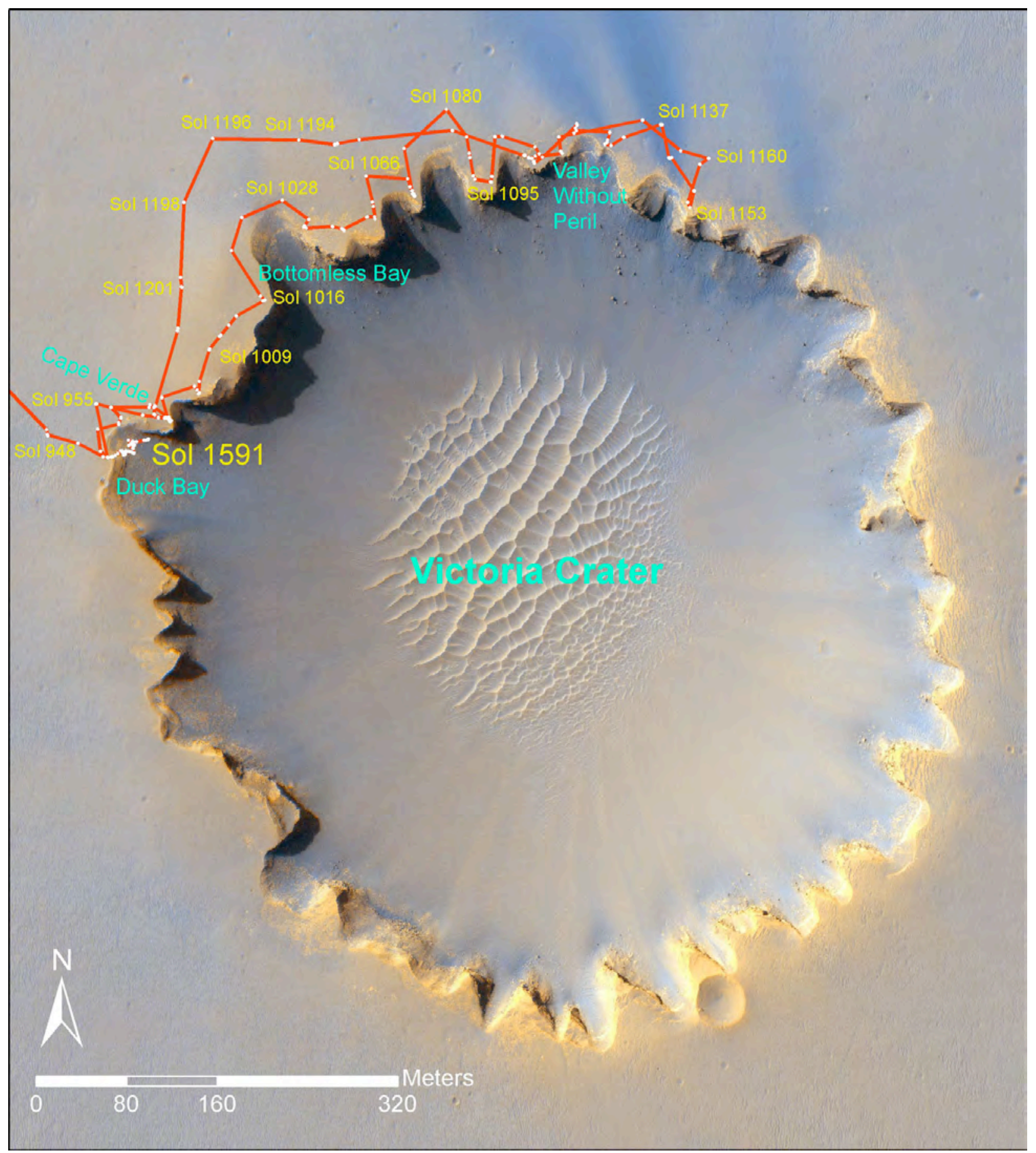

Figure 1: Opportunity's traverse at Victoria Crater. Image acquired by the Mars Reconnaissance Orbiter HiRISE camera. 


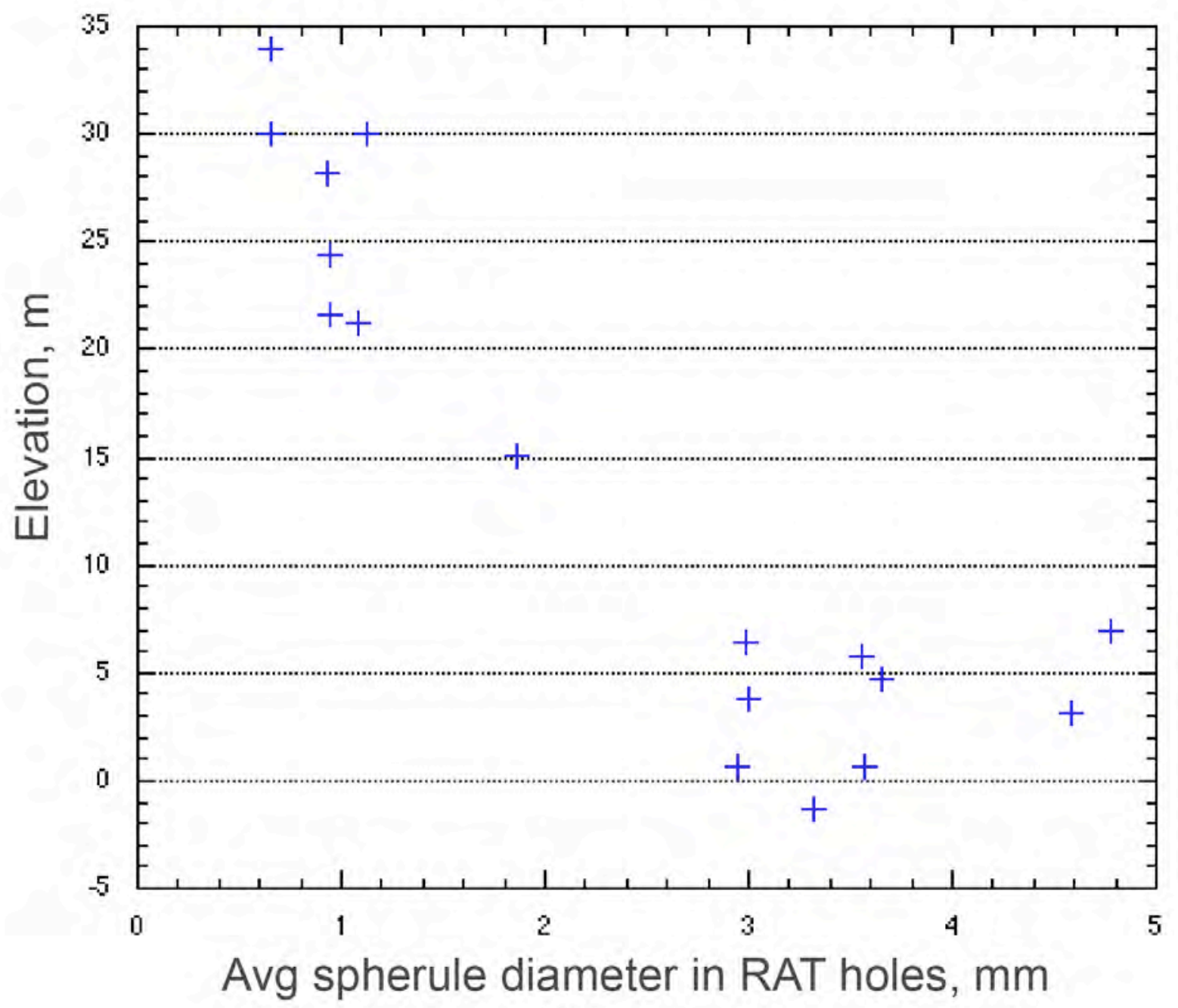

Figure 2. Diameter of spherules observed in RAT-abraded rock surfaces vs. elevation along Opportunity's southward traverse. The landing site elevation is defined to be $0 \mathrm{~m}$. Elevations were determined from a combination of least squares adjusted rover telemetry data, rover imagederived traverse data, and MOLA data. Elevation errors are within $3 \mathrm{~m}$. 

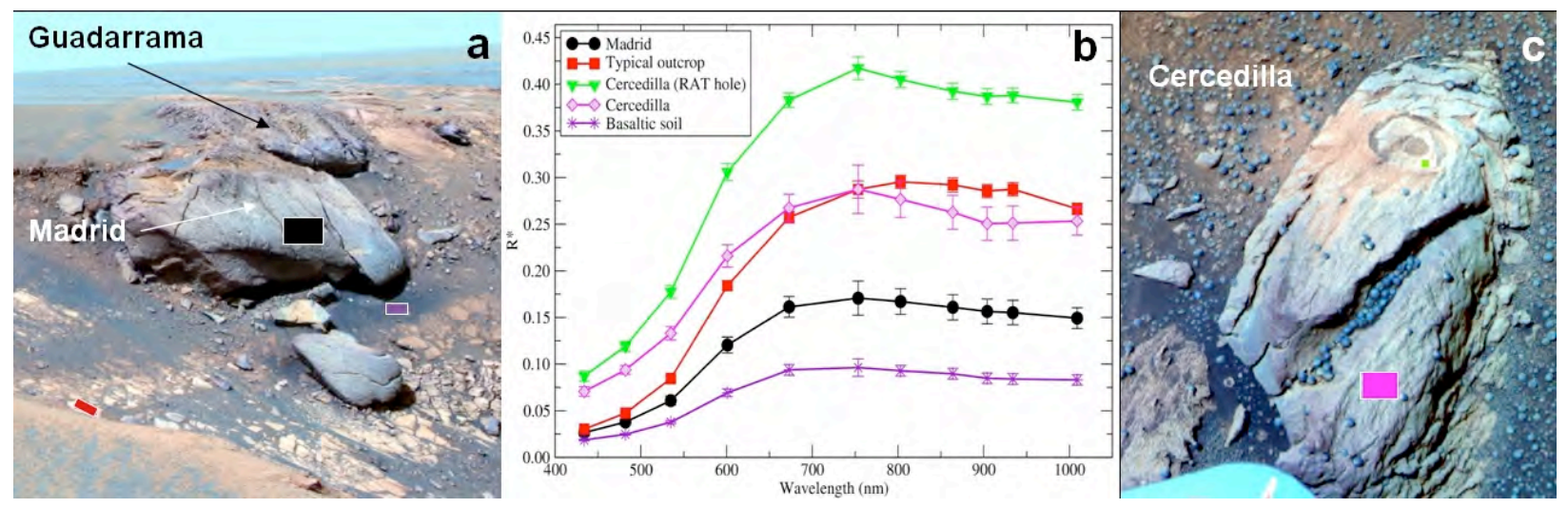

Figure 3. (a) Pancam false-color image (red $=753 \mathrm{~nm}$, green $=535 \mathrm{~nm}$, blue $=432 \mathrm{~nm})$ of Madrid and Guadarrama (sequence p2579, Sol 1079); (b) Pancam spectra $\left[\mathrm{R}^{*}=(\mathrm{I} / \mathrm{F}) / \cos (\right.$ incidence angle) $]$ of regions outlined in (a) and (c); (c) Pancam false-color image $($ red $=753 \mathrm{~nm}$, green $=535 \mathrm{~nm}$, blue $=432 \mathrm{~nm})$ of Cercedilla (sequence p2564, Sol 1184), showing area abraded by RAT at top. 


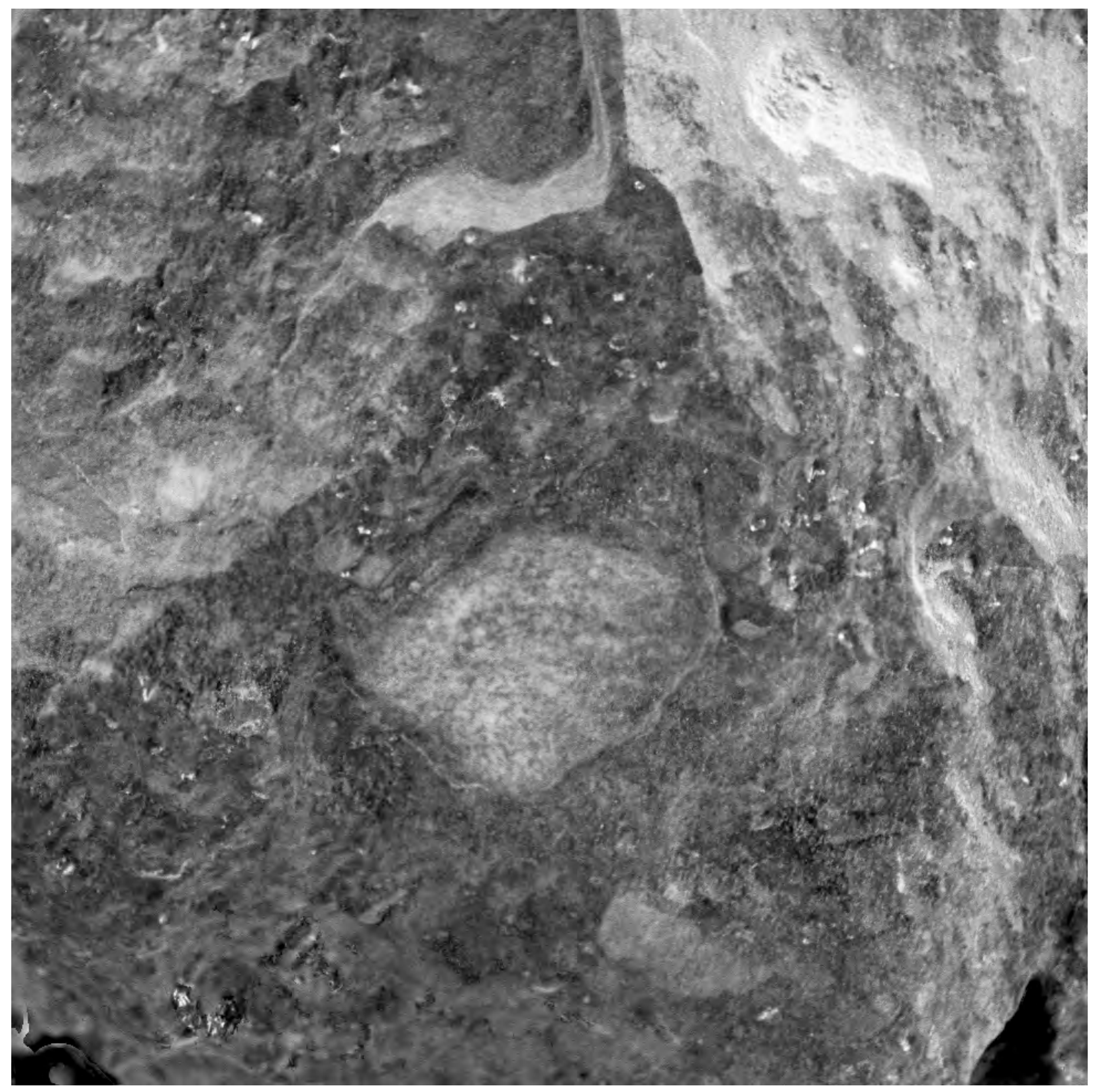

Figure 4. MI image of Santa Catarina, showing a brecciated appearance and possible igneous quench textures within clasts. The image is $3 \mathrm{~cm}$ across, and merges the best-focused portions of five MI images acquired on Sol 1055. 


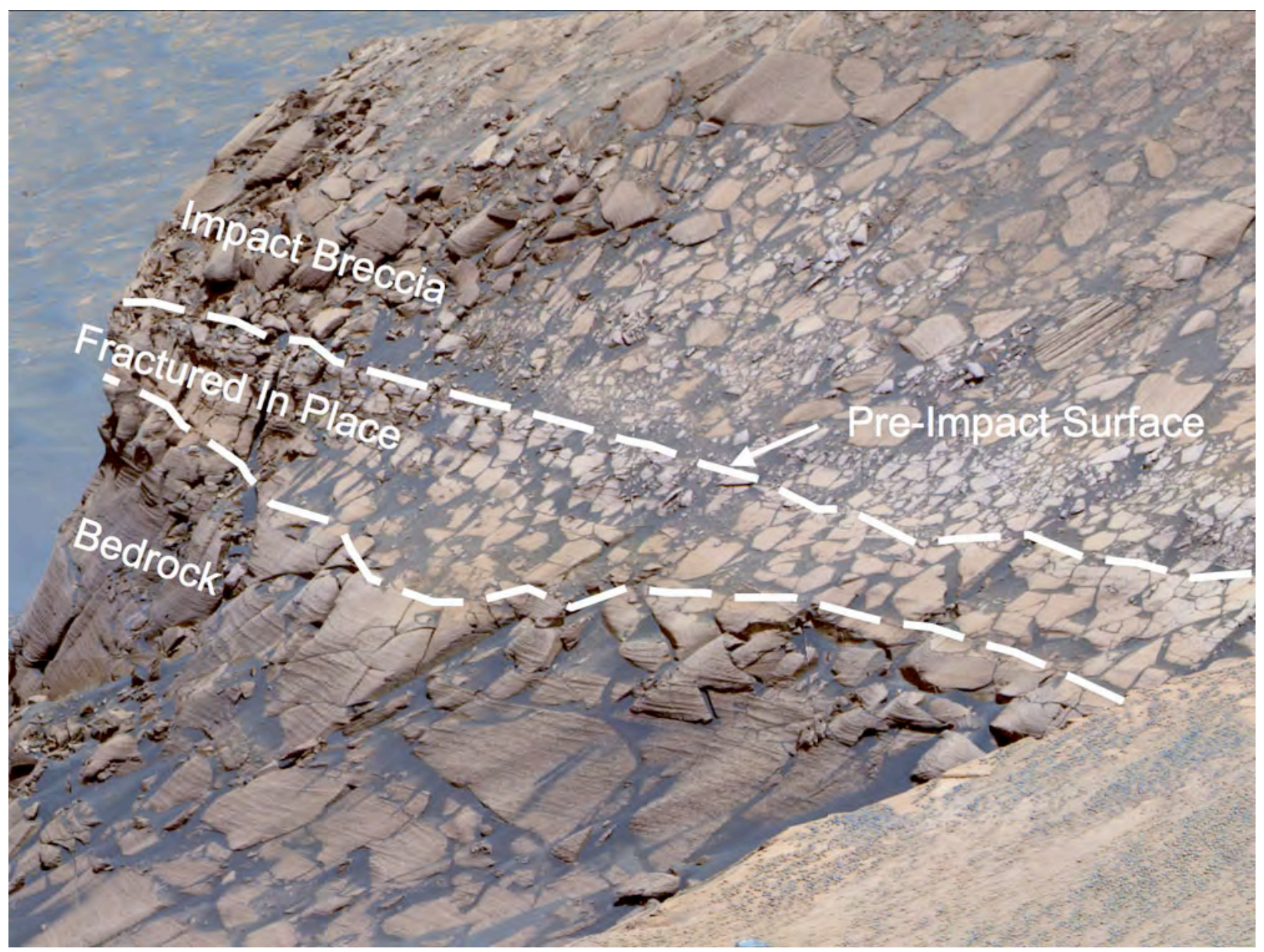

Figure 5. Pancam false color image $(\mathrm{red}=753 \mathrm{~nm}$, green $=535 \mathrm{~nm}$, blue $=432 \mathrm{~nm})$ of the east face of Cape Verde, showing typical impact-related stratigraphy observed in the upper bedrock walls of Victoria crater (sequence p2429, Sol 1006). 


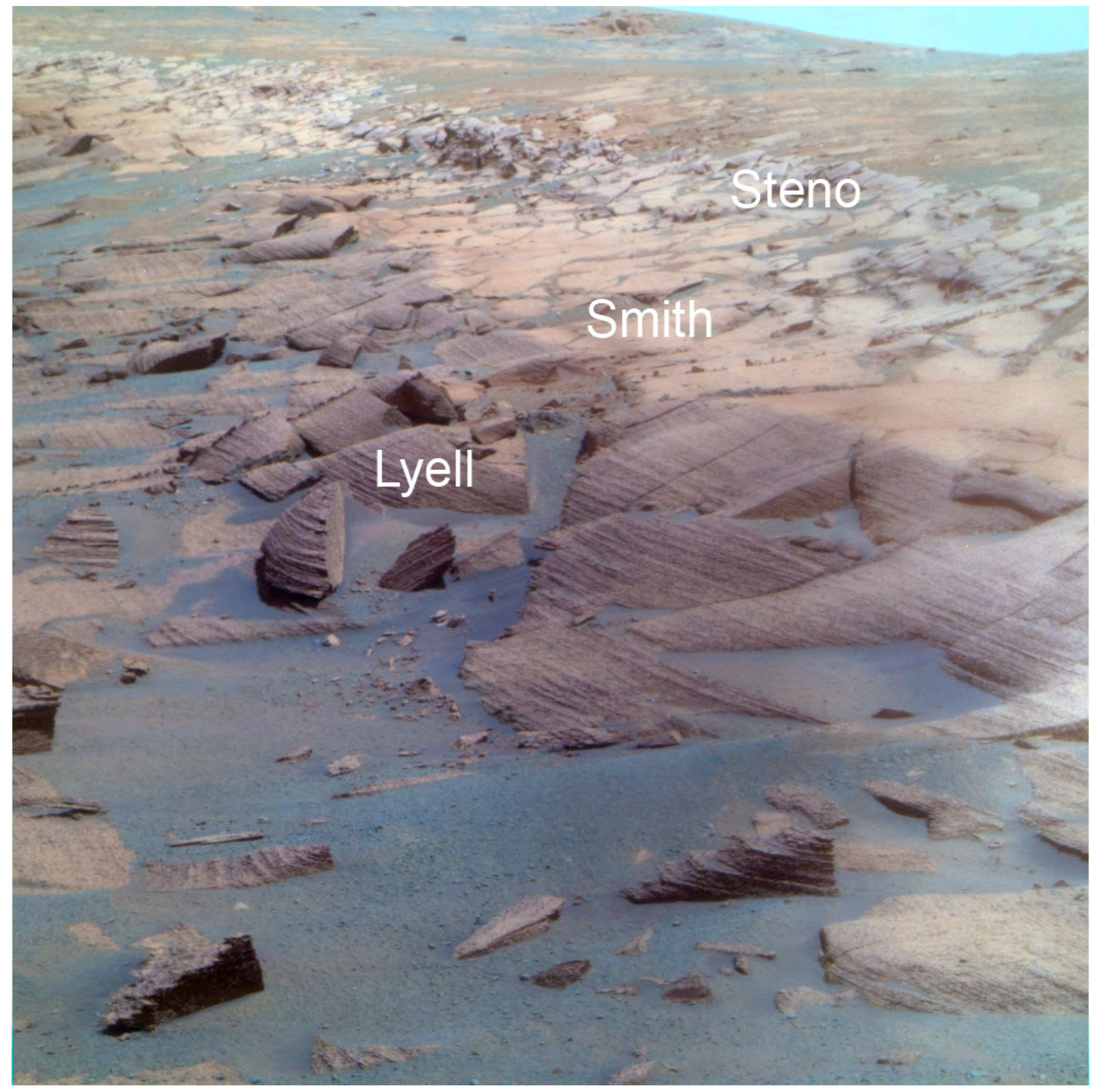

Figure 6. Pancam false color image $(\mathrm{red}=673 \mathrm{~nm}$, green $=535 \mathrm{~nm}$, blue $=432 \mathrm{~nm})$ of rocks at Duck Bay, showing the distinctive color stratigraphy observed ubiquitously in the upper bedrock walls of Victoria crater (sequence p2422, Sol 1426). 

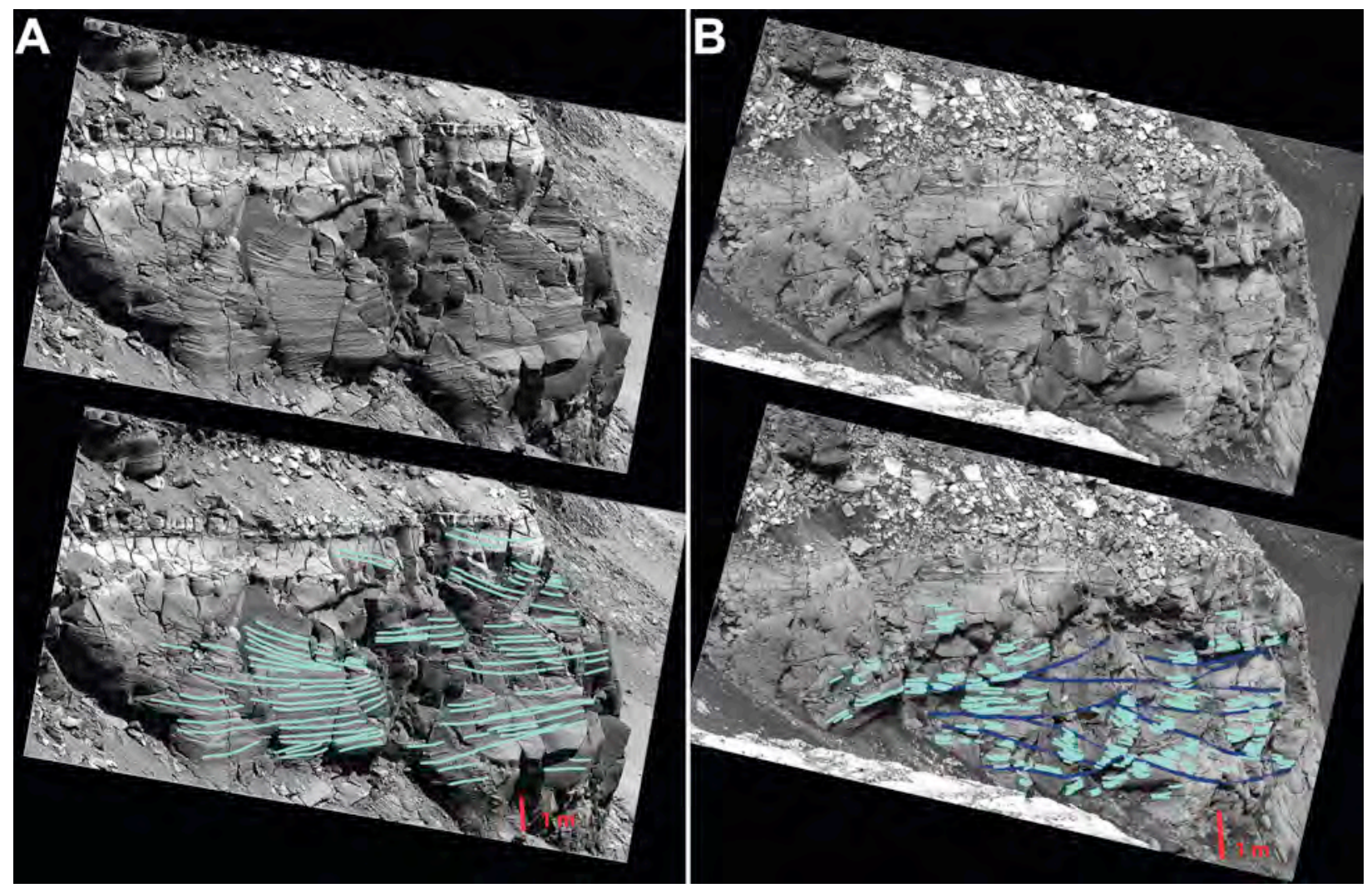

Figure 7. Pancam "super-resolution" images of cross stratification exposed on cliff faces at Cape St. Vincent (A, sequence p2417, Sol 1167) and Cape St. Mary (B, sequence p2444, Sol 1213). Lower images have bedding and cross stratification highlighted in blue. 


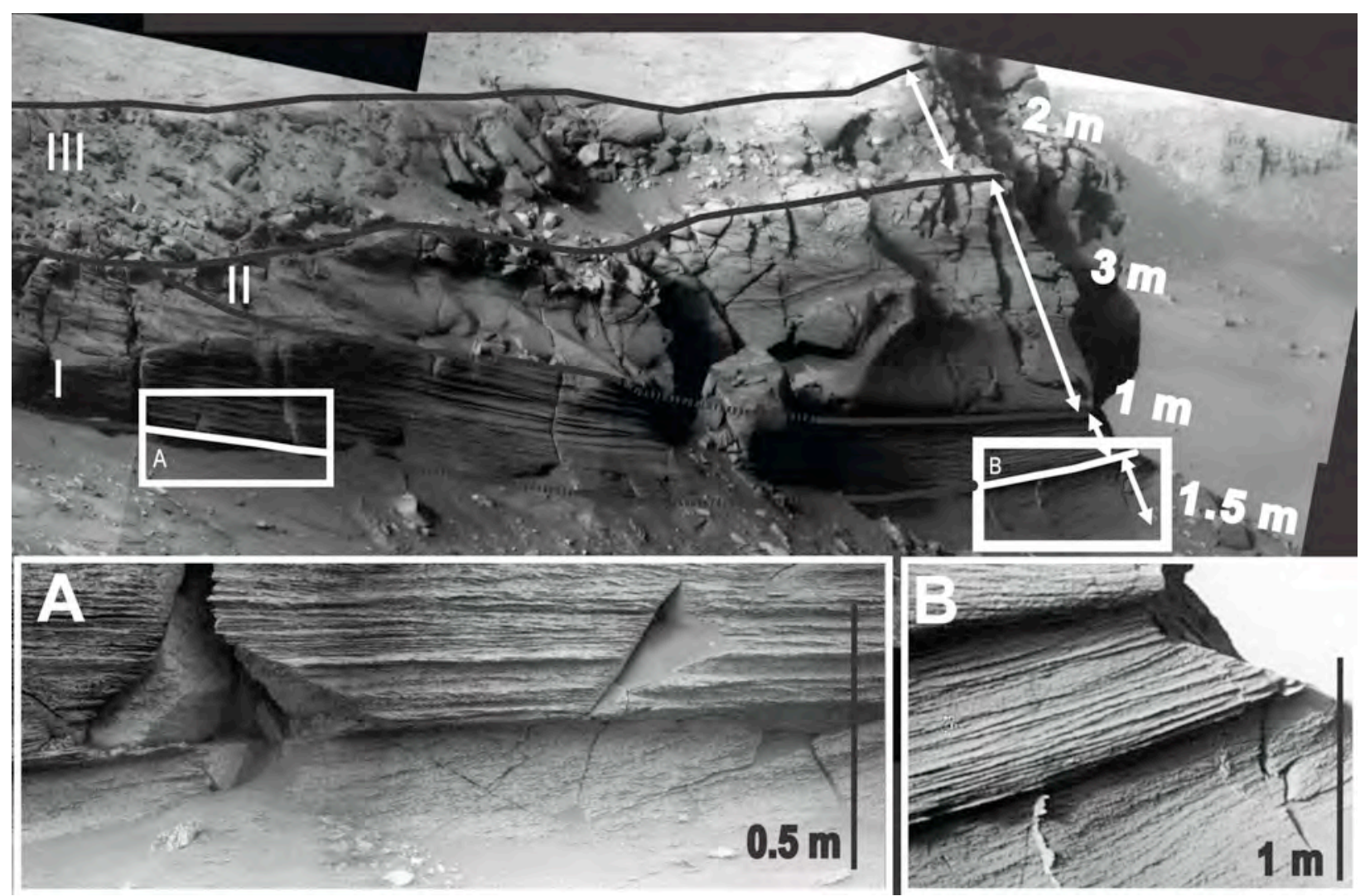

Figure 8. Pancam "super-resolution" image of Cape Verde (sequence p2396, Sol 1392). Unit I is interpreted as thickly-bedded dune toeset laminae, and unit II as dune foreset cross-stratification formed of climbing translatent strata with possible superimposed wind ripples. Unit III is impact breccia. Insets A and B show a probable erosional contact. Note truncated fracture fill in inset B, providing evidence for an erosional surface. 


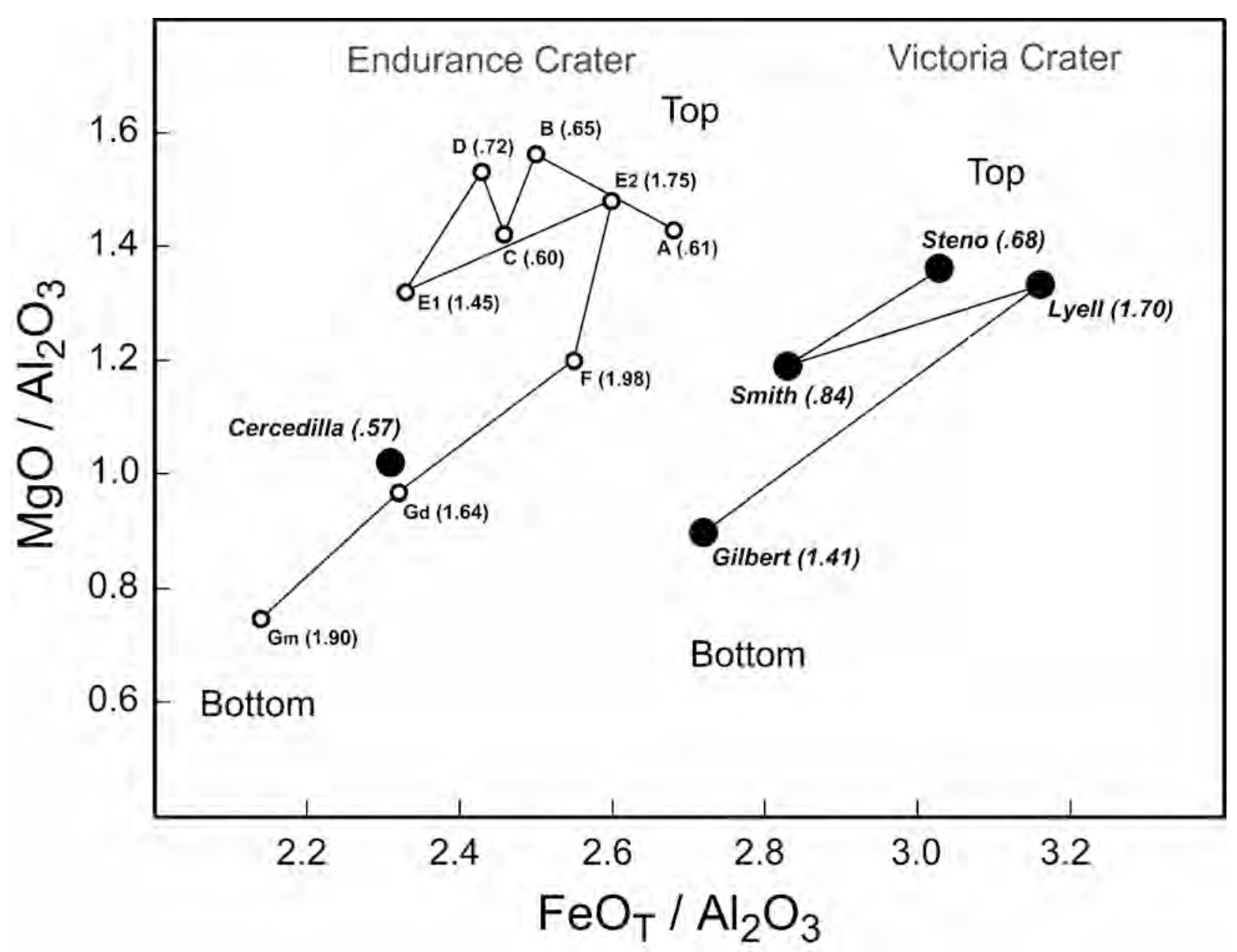

Figure 9. Plot of $\mathrm{MgO} / \mathrm{Al}_{2} \mathrm{O}_{3}$ vs. $\mathrm{FeO}_{\mathrm{T}} / \mathrm{Al}_{2} \mathrm{O}_{3}$. Plotted are analyses for targets fully abraded by the RAT from Endurance crater (small open circles) and Victoria crater (large closed circles). Samples are joined in stratigraphic order from top to bottom. In parentheses beside the sample names are $\mathrm{Cl}$ concentrations in weight percent. Also plotted is the rock Cercedilla found near the rim of Victoria crater. 